\title{
Validation and application of a new microwave-digestion/ICP-MS method for the analysis of trace metals in tree increment cores
}

\author{
JOHAN SCHIJF ${ }^{1 *}$ and MARY C. GARVIN ${ }^{2}$ \\ ${ }^{1}$ University of Maryland Center for Environmental Science, Chesapeake Biological Laboratory, \\ P.O. Box 38, Solomons, MD 20688, U.S.A. \\ ${ }^{2}$ Oberlin College, Department of Biology, Science Center K123, 119 Woodland Street, Oberlin, OH 44074, U.S.A.
}

(Received October 6, 2017; Accepted February 15, 2018)

\begin{abstract}
A method is presented for the routine analysis of eight trace metals ( $\mathrm{As}, \mathrm{Cd}, \mathrm{Co}, \mathrm{Cr}, \mathrm{Cu}, \mathrm{Ni}, \mathrm{Pb}, \mathrm{V}$ ) in wood samples of $100-200 \mathrm{mg}$. The organic matrix is broken down by microwave digestion and the resulting solutions are analyzed by ICPMS, after appropriate dilution, against an external multi-element calibration line. Detection limits are $200 \mathrm{ng}$ metal per $\mathrm{g}$ of dry wood for $\mathrm{Cr}$ and $\mathrm{Cu}$, and as low as $10-60 \mathrm{ng} \mathrm{g}^{-1}$ for the other six metals. Frequent analysis of the Certified Reference Material NJV 94-5 (Wood Fuel) and a series of spike recovery experiments gave chemical yields ranging from $90 \%$ for $\mathrm{Cr}$ to $103 \%$ for $\mathrm{V}$, but only $80 \%$ for As. Precision is generally $2-7 \%$, yet better for Cd and $\mathrm{Cu}(\sim 1 \%)$ and somewhat worse for As $(\sim 20 \%)$. This new method is suitable for the analysis of tree increment cores cut into sections representing 1-5 years of growth and can be readily modified to include additional metals. As a practical application, increment cores of eastern cottonwood (Populus deltoides) from Ohio (USA) were analyzed for the period 1970-2009. Pairwise comparisons of cores taken from the same tree, or from adjacent trees at the same location, illustrate some acknowledged limitations of their use as a temporal record of trace metal loading in soils.
\end{abstract}

Keywords: eastern cottonwood, trace metals, geochemical record, microwave digestion, ICP-MS

\section{INTRODUCTION}

Trees have long been studied as potential natural records of trace metal loading and bioavailability in soils. Reports on the presence of trace metals in ashed arboreal tissue date back to the late 19th century (Cossa, 1879; Heckel, 1899), but systematic studies had to await the development of sensitive analytical instruments and methods. Early assays relying on arc spectrography (Scribner, 1939) suffered from very poor detection limits, requiring as much as $100 \mathrm{~g}$ of dry matter, and thus focused predominantly on trace metal contents of tree leaves (Robinson et al., 1938, 1958). In order to exploit trees as a temporal record of their geochemical environment, a discipline referred to as "dendroanalysis" (Nabais et al., 1999), it is desirable to measure trace metal concentrations along a cross-section of the trunk. The use of an increment borer allows the entire life history of a mature tree to be accessed in a single sample without causing it permanent damage, but individual annual rings within the extracted core may weigh only tens of $\mathrm{mg}$. With concen-

\footnotetext{
*Corresponding author (e-mail: schijf@umces.edu)

Copyright () 2018 by The Geochemical Society of Japan.
}

trations ranging from tens of ng per $\mathrm{g}$ of dry wood for trace metals to hundreds of $\mu \mathrm{g} \mathrm{g}^{-1}$ for the alkaline earths (Olsson et al., 1999), a multi-element technique is required that combines excellent detection limits with a large dynamic range.

Modern approaches to trace metal analysis of tree cores fall in two categories. One is the use of non-destructive surface spectroscopic techniques such as secondary ion mass spectrometry (SIMS) (Martin et al., 1997), micro-synchrotron X-ray fluorescence ( $\mu \mathrm{SXRF}$ ) (Martin et al., 2006), or laser ablation ICP-MS (Hoffmann et al., 1994). Their main advantage is outstanding spatial resolution due to a typical beam size of $\sim 100 \mu \mathrm{m}$, yet this can actually be perceived as a disadvantage, since heterogeneity on length scales much smaller than the width of a ring tends to obfuscate annual cycles (Brabander $e t$ al., 1999), a problem that also plagues other temporal geochemical records, like corals (Sinclair et al., 1998; Giry et al., 2010). More pertinent disadvantages are long analysis times, often inadequate detection limits, and a lack of suitable standards that may give rise to merely semi-quantitative results. Nonetheless, laser ablation ICPMS analysis has been used to convincingly link metal abundances or distributions in xylem and bark with known areal pollution histories (Watmough et al., 1997; Narewski et al., 2000). 
The second category involves complete digestion of tree rings manually dissected from the increment core and analysis via solution-based techniques such as graphite furnace atomic absorption spectrometry (GFAAS) (Olsson et al., 1999) or ICP-MS (Hall et al., 1990; Yu et al., 2007). The main advantages of this approach are superior detection limits, an appropriate level of spatial averaging, and a greatly simplified sample matrix causing fewer interferences. These must be balanced against lower temporal resolution, a higher risk of contamination from a proliferation of reagents and preparatory steps, plus the need to sacrifice the core.

Here we present a new method for measuring trace metal concentrations in small plugs of wood, which was designed for a comprehensive survey of poplar trees in Sandusky County (Ohio, USA), the location of a childhood cancer cluster (Sandusky Co. Health Dept. and Ohio Dept. of Health, 2011). It utilizes microwave digestion, followed by ICP-MS analysis of the diluted solutions for $\mathrm{As}, \mathrm{Cd}, \mathrm{Co}, \mathrm{Cr}, \mathrm{Cu}, \mathrm{Ni}, \mathrm{Pb}$, and $\mathrm{V}$, on an instrument with a reaction cell that suppresses polyatomic interferences for several of the lighter elements. Our method is rapid and generates low blanks for most analytes, while its precision and detection limits are similar to those published elsewhere (Matusiewicz and Barnes, 1985; Hall et al., 1990; Hoffmann et al., 1994). A notable refinement is the independent verification of accuracy and chemical yield through repeated analysis of a carefully chosen Certified Reference Material (CRM), either with the basic protocol or by means of spike recovery experiments. The method can be readily modified, or adapted for ICP-AES, to encompass additional trace metals or major elements. Detection limits can be lowered, to permit the analysis of single annual rings, by decreasing the amount of acid applied in the digestion and/or by adjusting the dilution factor.

Trees are thought to acquire trace metals primarily via their roots, either directly from surface water and groundwater or indirectly from aerosols deposited on the leaves and then mobilized and transferred to the soil by slightly acidic rainwater (Hagemeyer et al., 1986). For dendroanalysis to be a reliable proxy of environmental pollution, metals ideally must (i) accumulate in proportion to their concentration in the soil; (ii) accumulate only in the outermost annual ring during the growth year; and (iii) be retained within that ring for the life of the tree. While it seems that the first assumption is commonly satisfied (Hagemeyer et al., 1993, 1994a), there is ample evidence that the latter two are not (Hagemeyer et al., 1992; Trüby, 1995; Hagemeyer and Hübner, 1999; Edmands et al., 2001). Still, many dendroanalytical studies of polluted areas have claimed success (Robitaille, 1981; Berish and Ragsdale, 1985; Eklund, 1995; Sheppard et al., 2007). Balouet et al. (2009) concluded that dendroanalysis may meet accepted legal criteria for the use of evidence in litigation by expert witnesses, with some caveats.

Metal uptake in trees is interesting for other reasons too e.g., establishing long-term historical baselines (Jonsson et al., 1997), examining putative effects of metal toxicity on forest health (Berish and Ragsdale, 1985), or fine-tuning arboriculture for the phytoremediation of metal-contaminated soils (Zacchini et al., 2009; Wu et $a l ., 2010)$. Whereas the goal of our paper is not to settle this issue, the method enables us to illustrate certain limitations of dendroanalysis and explore an alternative strategy, by comparing replicate cores from single trees at three different sites, as well as a core from a second tree at one of these sites. A detailed discussion of the Ohio survey is reserved for a separate publication.

\section{DESCRIPTION OF THE METHOD}

\section{Coring}

A total of 54 eastern cottonwood (Populus deltoides) was sampled in the City of Clyde (Sandusky County, Ohio) and in rural areas to the west and northwest. The majority (39) were sampled in the summer of 2012 and the remaining 15 in the summer of 2013. We selected mature trees with a straight, unforked trunk and no low branches or prominent scars. Two cores were collected 4-5 feet off the ground with a new Haglöf increment borer (\#10-100-1027, $40 \mathrm{~cm}, \varnothing 5.15 \mathrm{~mm}$ ), one a few inches above the other. Its shaft was driven horizontally into the tree, aiming as near as possible for the center of the trunk, and well cleaned with isopropyl alcohol (Sigma-Aldrich) after every sample. To prevent contamination, the use of lubricants or anticorrosives on the borer was strictly avoided. Cores were individually packed in rigid plastic tubes with caps on both ends and taken to Oberlin College.

One core of each pair (hereafter called the analytical core) was immediately shipped on ice to Chesapeake Biological Laboratory (CBL). The duplicate (hereafter called the archive core) was removed from its tube and air-dried overnight. The dry core was glued into a wooden tray and the upper half planed with an electric sander, to accentuate the annual rings. Rings were counted under a stereomicroscope from the youngest ring, just inside the bark, to the end of the core or to the center of the trunk, and half-decades were marked in pencil on the edge of the tray. The annotated archive cores were mailed to CBL.

Eastern cottonwood is a diffuse-porous tree and the cores are uniform in color without a clear transition from heartwood to sapwood, although they can have darker and lighter sections. This makes the annual rings difficult to discern and counting was thus performed with the help of expert Dr. Gregory Wiles at the College of Wooster 
(Ohio, USA). The drought year of 1988, usually identifiable as a distinctly narrower ring, was used as a benchmark. Only cores representing at least 40 years of growth and without defects, like breaks, knots, or decay, were accepted for analysis. Cores from stunted trees sometimes spanned more than 50 years of growth, but rarely more than 60 .

At CBL, the analytical core was removed from its tube and dried in a class-100 laminar flow bench inside a clean air laboratory, for at least a week. After drying, the core was lightly dusted with a Kimwipe to dislodge any particles left by the borer. Drying sometimes caused slight warping of the core, but alignment with the archive core, using visual cues such as distinctive rings, color changes, and the sapwood-bark transition, indicated that it does not cause shrinking. The archive core could thus be used to enable dissection of the analytical core without risk of contamination from sanding or excessive handling. Using the pencil marks on the archive core tray as a guide, eight 5-year sections covering the period 1970-2009 were outlined on the analytical core by gentle notching with the sharp tip of an 11-cm Littauer bone cutter (Fine Science Tools, \#16152-11). The sections were then neatly separated with $16-\mathrm{cm}$ bone scissors (Fine Science Tools, \#16030-16). These tungsten carbide microsurgical implements were cleaned with isopropyl alcohol after every cut.

\section{Microwave digestion}

Trace Metal Grade concentrated nitric acid $\left(\mathrm{HNO}_{3}\right)$ was purchased from Fisher and Ultrex II $30 \%$ hydrogen peroxide $\left(\mathrm{H}_{2} \mathrm{O}_{2}\right)$ from Mallinckrodt Baker. Both were stored in the dark. Milli-Q water $(18.2 \mathrm{M} \Omega \mathrm{cm})$ was produced with a Millipore Direct-Q 3UV purification system. Whole cores (eight 5-year sections) were completely digested in a Milestone Ethos EZ microwave unit holding a 10-position carousel of acid-cleaned Teflon vessels with 30-mL quartz inserts (cup + lid). Each core section was placed in an insert and weighed on a Mettler Toledo AB104-S/FACT analytical balance to an accuracy of 0.1 $\mathrm{mg}$. Long sections were cut into smaller pieces to allow full submersion in the acid. Sections typically weighed 200-300 mg, but occasionally more than 400 or less than $100 \mathrm{mg}$. The ninth insert was loaded with $150-450 \mathrm{mg}$ of CRM NJV 94-5 (Wood Fuel), using a Teflon-coated metal spatula. The tenth insert stayed empty and served as a procedural blank.

Depending on the growth rate of the tree i.e., the average size of the sections, either 8 or $10 \mathrm{~mL}$ of concentrated $\mathrm{HNO}_{3}$ was pipetted into each insert. The insert with the CRM was gently swirled to wet the floating powder. The quartz cups were transferred to the Teflon vessels and covered with the quartz lids. Next, $10 \mathrm{~mL}$ of Milli-Q water and $2 \mathrm{~mL}$ of $30 \% \mathrm{H}_{2} \mathrm{O}_{2}$ were pipetted on the out- side of each insert and the vessels closed to the correct torque with a Milestone Twister module. The carousel was assembled, placed in the microwave, and then heated under constant rotation. Samples were linearly ramped to $200^{\circ} \mathrm{C}$ in $10 \mathrm{~min}$, maintained at $200^{\circ} \mathrm{C}$ for $10 \mathrm{~min}$, and cooled inside the microwave for at least 100 min under continued rotation and forced airflow, until a safe temperature of $<50^{\circ} \mathrm{C}$ was reached. The temperature was monitored with a thermocouple at one carousel position not containing the procedural blank.

The Teflon vessels were cautiously opened with the Twister module to ensure controlled venting of any pressurized nitrous fumes. The inserts were removed from the vessels with plastic forceps and their outsides rinsed with Milli-Q water and dried with a Kimwipe. Solutions left in the vessels were discarded as they were shown to contain no trace metals. No solid residue was ever seen in the digests, which were normally clear and pale yellow. The inserts were set in a rack and cooled to room temperature overnight. The vessels were rinsed with Milli-Q water and dried in the laminar flow bench.

The following morning, each insert was weighed and its pre-recorded tare weight, registered by numbers engraved on the paired quartz cup and lid, was subtracted to derive the digest weight. Tare weights were regularly checked and found to change by no more than $0.5 \mathrm{mg}$ over the 2-year duration of the project. Using a pipette, 1 $\mathrm{mL}$ of the digest was weighed in an acid-cleaned $30-\mathrm{mL}$ Teflon PFA vial (Savillex) to determine its density (1.35$1.40 \mathrm{~g} \mathrm{~mL}^{-1}$ ), whereupon the rest of the digest was added to the vial. Empty inserts were rinsed with Milli-Q water and dried in the laminar flow bench. Digest weights were divided by densities to obtain accurate final volumes that accounted for evaporative losses of up to $\sim 25 \%$.

After extended periods of disuse, or if the microwave had been reserved for a different project, the vessels and inserts were more thoroughly cleaned by assembling the carousel with the aforementioned reagents (except only $5 \mathrm{~mL}$ of $\mathrm{HNO}_{3}$ in the inserts) and running a cleaning program (ramp to $120^{\circ} \mathrm{C}$ in $10 \mathrm{~min}$, maintain at $120^{\circ} \mathrm{C}$ for 10 min). Disassembled Teflon and quartz parts were rinsed and dried as described above.

\section{ICP-MS analysis}

Digests were analyzed for trace metals on an Agilent 7500cx ICP-MS equipped with an Octopole Reaction System (ORS), a quartz Scott-type spray chamber, and a glass Meinhardt-type nebulizer. Prior to analysis, digests were diluted 100 -fold (some 50 -fold) with $1 \% \mathrm{HNO}_{3}$ to lower the acid strength and suppress matrix effects, and mixed with a pre-made internal standard solution to obtain $8 \mathrm{ng} \mathrm{mL}^{-1}$ of Ge and $2 \mathrm{ng} \mathrm{mL}^{-1}$ of In and Re. Concentrations of $\mathrm{As}, \mathrm{Cd}, \mathrm{Co}, \mathrm{Cr}, \mathrm{Cu}, \mathrm{Ni}, \mathrm{Pb}$, and $\mathrm{V}$ were measured against external 5 -point calibration lines, made 
Table 1. Operating conditions of the Agilent $7500 \mathrm{cx}$ ICP-MS

\begin{tabular}{ll}
\hline ICP-MS setting & \\
Ar plasma flow & $15 \mathrm{~L} / \mathrm{min}$ \\
Ar auxiliary flow & $1 \mathrm{~L} / \mathrm{min}$ \\
Ar nebulizer flow & $1.05 \mathrm{~L} / \mathrm{min}$ \\
forward power & $1100 \mathrm{~W}$ \\
reflected power & $<5 \mathrm{~W}$ \\
sample and skimmer cone & $\mathrm{Ni}$ \\
nebulizer & MicroMist concentric \\
Capricorn Ar humidifier & on \\
sample depth & $7.8 \mathrm{~mm}$ \\
pump rate & $0.1 \mathrm{rps}$ \\
spray chamber & double pass \\
spray chamber temperature & $2{ }^{\circ} \mathrm{C}$, Peltier-cooled \\
oxide ions $\left(\mathrm{CeO} \mathrm{O}^{+} / \mathrm{Ce}^{+}\right)$ & $<1 \%$ \\
double-charged ions $\left(\mathrm{Ce} \mathrm{e}^{2+} / \mathrm{Ce}^{+}\right)$ & $<2 \%$ \\
Octopole Reaction System $(\mathrm{ORS})$ & $\mathrm{He} 5.6 \mathrm{~mL} /$ min \\
& \\
Method parameters & \\
analysis & multi-tune, hot plasma \\
detector & pulse counter \\
mode stabilization time & $60 \mathrm{~s}$ \\
pre-emptive rinse & $15 \mathrm{~s}$ \\
dwell time & variable* \\
points per peak & 3 \\
number of repetitions & 3 \\
VIS** interpolation & off \\
weighted calibration & off \\
\hline
\end{tabular}

*As, Co $,{ }^{52} \mathrm{Cr}, \mathrm{Cu},{ }^{60} \mathrm{Ni}, \mathrm{V}: 0.6 \mathrm{~s} ;{ }^{53} \mathrm{Cr},{ }^{61,62} \mathrm{Ni}: 1.2 \mathrm{~s} ; \mathrm{Cd}, \mathrm{Pb}: 1.8 \mathrm{~s}$ **Virtual Internal Standard.

in 250-mL Teflon bottles from a multi-element stock solution (SPEX CertiPrep, CLMS-2AN, $10 \mu \mathrm{g} \mathrm{mL}^{-1}$ in $5 \%$ $\mathrm{HNO}_{3}$ ) and containing the same internal standards. Zinc analysis was abandoned in light of prohibitive contamination problems. A fresh set of calibration standards was prepared every few weeks, a total of ten times over the course of the project, to limit evaporation and the gradual accumulation of blanks. Regressions of the calibration data were consistently linear $\left(r^{2}>0.999\right)$ with minimal intercepts. The ICP-MS operating conditions are summarized in Table 1.

Isotopes acquired for each of the eight metals are shown in Table 2. Concentrations of $\mathrm{Cd}, \mathrm{Co}, \mathrm{Cu}$, and $\mathrm{Pb}$ were measured under robust plasma conditions. Their isotope signals were normalized to ${ }^{115} \mathrm{In}(\mathrm{Cd}),{ }^{72} \mathrm{Ge}$ (Co and $\mathrm{Cu})$, and ${ }^{185} \mathrm{Re}(\mathrm{Pb})$, to correct for instrumental drift. Concentrations of $\mathrm{As}, \mathrm{Cr}, \mathrm{Ni}$, and $\mathrm{V}$ were measured using the ORS $(5.6 \mathrm{~mL} / \mathrm{min}$ of $\mathrm{He})$ to eliminate polyatomic interferences from $\mathrm{ArCl}^{+}(\mathrm{As}), \mathrm{ClO}^{+}$and $\mathrm{ArN}^{+}(\mathrm{Cr}$ and $\mathrm{V})$, and $\mathrm{CaO}^{+}(\mathrm{Ni})$. Their isotope signals were all normalized to ${ }^{72} \mathrm{Ge}$. Concentrations calculated from different isotopes acquired for the same metal were generally in good agreement and therefore averaged. Concentrations of $\mathrm{Pb}$ were calculated from the sum signal of ${ }^{206} \mathrm{~Pb}+{ }^{207} \mathrm{~Pb}+{ }^{208} \mathrm{~Pb}$ to account for variation in its natural isotopic abundances.

The ICP-MS was tuned for optimum signal intensity and low fractions of oxide and double-charged ions with a $1 \mathrm{ng} \mathrm{mL}-1$ solution of ${ }^{7} \mathrm{Li},{ }^{59} \mathrm{Co},{ }^{89} \mathrm{Y},{ }^{140} \mathrm{Ce}$, and ${ }^{205} \mathrm{Tl}$ in $1 \% \mathrm{HNO}_{3}$. A separate tuning file was generated for the ORS mode using the same solution in 5\% $\mathrm{HCl}$. For each standard or sample solution, the ICP-MS started in robust mode to analyze the first four metals and automatically switched to ORS mode to analyze the other four, after a 60 -s stabilization. The outside of the autosampler probe was then rinsed with $1 \% \mathrm{HNO}_{3}$ for $5 \mathrm{~s}$, followed by a 30 -s rinse with the calibration blank to clean the entire sample introduction system. Since the contents of tubing connecting the autosampler to the ICP source can sustain isotope signals for more than $30 \mathrm{~s}$, "pre-emptive" rinsing was initiated $15 \mathrm{~s}$ before the end of data acquisition, to shorten the ICP-MS runs.

One of the calibration standards was analyzed at random after every ICP-MS run to affirm the validity of the drift correction. Suites of diluted digests were run twice in arbitrary order, but always starting with the procedural blank(s). Fresh dilutions of the same digests were then run again, if necessary, for up to five analyses per core. Digests showing poor reproducibility for a specific metal, particularly concentrations that steadily increased in successive runs, were reanalyzed more often, to assess whether contamination occurred during dilution or at an earlier stage. Final concentrations, corrected for the procedural blank and dilution factor and averaged over all isotopes and analyses after removal of outliers, were divided by the sample weight and multiplied by the digest volume to convert units of ng metal per $\mathrm{mL}$ of solution to ng metal per $g$ of dry wood. The CRM concentrations were further multiplied by a factor 1.068 to correct for moisture content.

Analysis of the CRM initially conveyed low chemical yields for As and Cr. Since certified values were not available for $\mathrm{Ni}$ and $\mathrm{V}$, a series of spike recovery experiments was devised to distinguish between digestion losses of just As and $\mathrm{Cr}$, or a failure of the ORS to suppress polyatomic interferences on all four metals. A stock solution of the four metals was made from single-element standards (SPEX CertiPrep, $1,000 \mu \mathrm{g} \mathrm{mL}^{-1}$ in $2 \% \mathrm{HNO}_{3}$ ). Ten CRM samples and a procedural blank were spiked before digestion with $250-2000 \mu \mathrm{L}$ of this solution, keeping the total volume constant. Another CRM sample, procedural blank, and one core section were spiked after digestion. One procedural blank was spiked after digestion with CLMS-2AN, comprising all eight metals. The spiked samples were digested, diluted, and analyzed like unspiked samples. The two spike solutions were also analyzed directly, to verify their concentrations. The 4metal stock solution contained no detectable levels of the other four metals. 
Table 2. Data acquisition and figures of merit

\begin{tabular}{|c|c|c|c|c|c|}
\hline Metal & Isotopes & $\mathrm{ORS}^{\mathrm{a}}$ & Blank correction & Detection limit $\left(\mathrm{ng} \mathrm{g}^{-1}\right)^{\mathrm{b}}$ & Median precision (\%RSD) \\
\hline As & 75 & yes & yes & 53 & 21 \\
\hline $\mathrm{Cd}$ & $110,111,112$ & no & yes & 10 & 0.66 \\
\hline Co & 59 & no & no & $64(51)^{\mathrm{c}}$ & 3.1 \\
\hline $\mathrm{Cr}$ & 52,53 & yes & no & $249(175)^{\mathrm{c}}$ & 3.5 \\
\hline $\mathrm{Cu}$ & 63,65 & no & yes & 243 & 1.4 \\
\hline $\mathrm{Ni}$ & $60,61,62$ & yes & yes & 59 & 3.9 \\
\hline $\mathrm{Pb}$ & $206+207+208^{d}$ & no & yes & 30 & 2.4 \\
\hline $\mathrm{V}$ & 51 & yes & yes & 25 & 6.5 \\
\hline
\end{tabular}

\section{RESULTS AND DISCUSSION}

\section{Sample preparation}

For our method, we selected microwave digestion in pressurized vessels, rather than hotplate digestion in open beakers, because it is widely available, quicker and safer, has lower blanks, and ensures better recovery of volatile elements (with the exception of As, see below). No attempt was made to optimize the protocol prescribed by the manufacturer. Typical core sections of $200 \mathrm{mg}$ were digested in $8 \mathrm{~mL}$ of concentrated $\mathrm{HNO}_{3}$, equivalent to the use of $1 \mathrm{~mL}$ per $25 \mathrm{mg}$ wood recommended by Sheppard et al. (2007). Some methods require smaller amounts (e.g., $3 \mathrm{~mL}$ per $250 \mathrm{mg}$; Hall et al., 1990), yet we observed that 8 -mL digests of samples $>350 \mathrm{mg}$ display an intense emerald-green color. The unknown culprit may be a blue aromatic nitrogen compound that looks green against the yellow background of dissolved nitrogen dioxide gas. Since this could well be a sign of incomplete reaction, larger core sections were subsequently digested in $10 \mathrm{~mL} \mathrm{HNO}_{3}$. While the effect recurs at times with samples from unusually fast-growing trees, the green color dissipates upon cooling, the solution is otherwise clear, and trace metal analysis does not appear to be compromised.

Prior to digestion, whole increment cores were airdried in a laminar flow bench for one week. No heating or ashing was employed, in order to prevent contamination or loss of volatile elements. The moisture content of the CRM was estimated by drying three separate batches of about $1 \mathrm{~g}$ in an oven at $90^{\circ} \mathrm{C}$ for up to a week, inside covered quartz inserts. The batches were weighed daily until a constant mass was attained. The moisture content was found to be $6.8 \pm 0.7 \%$, consistent with $5 \%$ reported for air-dried wood by Harju et al. (1997) and with a dry matter content of $94 \%$ stated in the CRM documents. Rather than drying the CRM samples, their recorded weights were adjusted to account for residual moisture.
Such a correction was not applied to core sections, whose metal concentrations should thus be considered lowerbound values. It must be emphasized that the calculation of metal burdens (see Subsection "Application to natural samples") circumvents the residual moisture correction altogether.

Preparing the core samples for digestion and assembling the microwave carousel takes about 1 hour. Whereas the digestion itself requires a mere $20 \mathrm{~min}, 2$ hours are needed to cool the Teflon vessels to a safe temperature. With proper precautions to avoid contamination, this step may be expedited by placing the vessels in an ice bath. Retrieving the inserts and rinsing the vessels takes another hour. If the vessels are not dried, a single analyst could in principle process two whole increment cores per day, although that may increase the risk of contamination. Our final protocol involves preparation and digestion of the samples and rinsing of the vessels in an afternoon, followed by overnight cooling of the inserts and drying of the vessels. The digests are weighed, diluted, and analyzed the next morning, so that a new cycle can begin on the same day. In summary, under routine operation, a single analyst with access to at least two sets of quartz inserts can achieve end-to-end metal analysis of one increment core per day, on average.

In dendrochronological research it is customary to take multiple cores from opposite sides of the tree, so that missing or double annual rings and other artifacts may be revealed (e.g., Fritts, 1976). For our approach it is essential that the archive and analytical cores are taken from the same side and close together, to make them as equal as possible. Although the cores were not all recovered in the same year, the removal of all annual rings past 2009 and the use of obvious temporal markers such as the 1988 drought year aids their accurate alignment. Hagemeyer et al. (1992) compared metal profiles in sets of four cores, taken simultaneously from a single tree, either from the same direction with minimal vertical spacing, or from 
perpendicular directions at the same height. They showed that in each case there may be minor variations in metal abundance, but not in metal distribution along the core.

\section{Precision, blanks, and detection limits}

Precision of the metal concentrations was estimated from frequent analysis of the CRM and from replicate measurements of core sections. The CRM analyses were fairly invariant and an outlier criterion of three standard deviations of the mean resulted in just one or two rejected points for each metal. Measurement of the sections was much more noisy and skewed, hence a criterion of ten standard deviations was used for rejection. Outliers were most common for $\mathrm{Cu}$ and $\mathrm{Pb}$, and always higher than the mean, indicating they were caused by random contamination (probably during core collection, which does not affect the CRM). Typical precision after removal of outliers was $\sim 1 \%$ for $\mathrm{Cd}$ and $\mathrm{Cu}, \sim 20 \%$ for As, and $2-7 \%$ for the other five metals (Table 2).

Calibration lines, comprising four standards and a blank, were stored and used repeatedly to increase throughput. The lines degraded, due to evaporation and the gradual accumulation of blanks from regular handling, and were replaced after every 15-20 ICP-MS runs ( 2 weeks). The degree of degradation was monitored by analyzing the old calibration standards as samples against the new line and generally stayed within the aforementioned precision for each metal, except on occasion for the lowest two standards. Residual degradation, discernible as a slowly accreting intercept, as well as trace contaminants in the matrix acid were accounted for by the inclusion of a blank ("zero standard") in the calibration line. The consistently excellent quality of the CRM analyses confirms that these safeguards kept the degradation within acceptable limits.

The level of systematic, as opposed to random, contamination was estimated from the procedural blanks incorporated in each digestion run. Three types of blank correction were tried: no correction, correction with the procedural blank measured in the same ICP-MS run, or correction with the average of all procedural blanks measured using the same set of calibration standards. The CRM analyses, particularly the spike recovery experiments, revealed that the second option produces superior results for most metals. For Co, concentrations were often near the detection limit and blank corrections produced spurious negative values. For $\mathrm{Cr}$, procedural blanks were quite large and erratic, possibly because of an interference not sufficiently suppressed by the ORS, and any correction led to incongruous results and dubiously low chemical yields. Blank corrections were not performed for these two metals (Table 2).

Detection limits representative of the 100 -fold diluted digests were calculated as three times the standard devia-
Table 3. Chemical yield of CRM NJV 94-5

\begin{tabular}{lclcc}
\hline Metal & $\begin{array}{c}\text { CRM certified } \\
\left(\mu \mathrm{g} \mathrm{g}^{-1}\right)^{\mathrm{a}}\end{array}$ & $\begin{array}{c}\text { CRM measured } \\
\left(\mu \mathrm{g} \mathrm{g}^{-1}\right)^{\mathrm{a}}\end{array}$ & $n^{\mathrm{b}}$ & Yield (\%) \\
\hline $\mathrm{As}$ & $0.8 \pm 0.24$ & $0.6 \pm 0.1$ & 45 & 80 \\
$\mathrm{Cd}$ & $0.27 \pm 0.028$ & $0.265 \pm 0.005$ & 55 & 98 \\
$\mathrm{Co}$ & - & $0.079 \pm 0.009$ & 54 & - \\
$\mathrm{Cr}$ & $0.8 \pm 0.30$ & $0.53 \pm 0.07$ & 44 & $90^{\mathrm{c}}$ \\
$\mathrm{Cu}$ & $2.2 \pm 0.30$ & $2.1 \pm 0.2$ & 55 & 95 \\
$\mathrm{Ni}$ & $(4.0 \pm 0.7)^{\mathrm{d}}$ & $0.35 \pm 0.01$ & 45 & $99^{\mathrm{c}}$ \\
$\mathrm{Pb}$ & $0.68 \pm 0.025$ & $0.63 \pm 0.04$ & 54 & 93 \\
$\mathrm{~V}$ & - & $0.082 \pm 0.005$ & 45 & $103^{\mathrm{c}}$ \\
$\mathrm{Zn}$ & $38 \pm 8.5$ & - & - & - \\
\hline
\end{tabular}

${ }^{a} \mu \mathrm{g}$ per g of dry wood.

${ }^{b}$ Number of unspiked replicates after removal of outliers.

${ }^{c}$ Yield based on spike recovery.

${ }^{d}$ From Olsson et al. (1999).

tion of all procedural blanks ( $n \sim 170)$. These are comparable to values published for another solution-based ICPMS method (Hall et al., 1990) and were used to accept or reject the quantitation of individual digests. In Table 2, detection limits are converted to units of ng per $\mathrm{g}$ of dry wood for a nominal core section of $200 \mathrm{mg}$ digested in 8 $\mathrm{mL}$ of $\mathrm{HNO}_{3}$. Values for different isotopes of the same element are generally similar and consequently averaged. Detection limits for hypothetical blank-corrected samples are also shown for $\mathrm{Co}$ and $\mathrm{Cr}$. Note that detection limits expressed in these units are conditional i.e., a large core section with low metal concentration may be above the ICP-MS detection limit, whereas a small section with high concentration may not be if it contains a lesser total quantity of the metal.

Core sections were digested in concentrated $\mathrm{HNO}_{3}$. Evolving nitrous fumes are partly re-oxidized by a $5: 1$ mixture of water and $30 \% \mathrm{H}_{2} \mathrm{O}_{2}$ on the outside of the quartz insert, which keeps the pressure inside the Teflon vessels low and enhances the reactivity of the acid. Smaller core sections could potentially be digested with less $\mathrm{HNO}_{3}$, or with an equal volume of less concentrated $\mathrm{HNO}_{3}$. The latter would allow a lower dilution factor, so both would give rise to higher metal concentrations while diminishing the amount of acid used, resulting in lower procedural blanks and detection limits. We did not make these modifications, as our detection limits (Table 2) were mostly adequate for the purpose of the Ohio survey.

\section{Accuracy and chemical yield}

Unlike other studies, which have largely utilized leaf CRMs, we chose a wood CRM to gauge the accuracy of our method. Reference material NJV 94-5 (Wood Fuel) consists of ground, sieved $(<1 \mathrm{~mm})$, and homogenized pine waste from a Swedish saw mill with a 70:30 bark:chip 
ratio. Table 3 lists certified concentrations of $\mathrm{As}, \mathrm{Cd}, \mathrm{Cr}$, $\mathrm{Cu}$, and $\mathrm{Pb}$, included in our method, as well as $\mathrm{Zn}$, which was not analyzed. A value for Ni obtained via GFAAS analysis was reported by Olsson et al. (1999). No published data could be found for Co and V.

One or two CRM samples were digested with every tree core for a total of 56 analyses. To ensure that the accuracy of our method is insensitive to sample weight, the amount of CRM was varied over the same range as the core sections. The measurements given in Table 3 are averages of these analyses, calculated as specified below, whereby values more than three standard deviations above the mean were considered outliers. All are within the uncertainties reported for the CRM (Table 3) and generally at least $93 \%$ of the certified value. However, the measured value for $\mathrm{Ni}$ is more than one order of magnitude lower than that reported by Olsson et al. (1999). Concentrations of $\mathrm{Co}$ and $\mathrm{V}, 79$ and $82 \mathrm{ng} \mathrm{g}^{-1}$ respectively, are reported here for the first time. Both are very low, the former exceeding its method detection limit of $64 \mathrm{ng} \mathrm{g}^{-1}$ (Table 2) by only $23 \%$.

While still within their reported uncertainties, As and $\mathrm{Cr}$ had imperfect yields of $80 \%$ and $66 \%$, respectively. Since they are among the four metals that suffer polyatomic interferences, spike recovery experiments were performed in order to learn whether this was due to actual loss during digestion or to an ICP-MS problem. One CRM, two procedural blanks, and one core section were spiked after digestion and exhibited spike recoveries of 90-110\% (data not shown), when compared with the corresponding unspiked samples, indicating that the ORS worked properly.

Ten CRM samples were spiked before digestion and treated collectively like a standard addition experiment. The measured concentration of the spiked sample, C, can be expressed in terms of the CRM concentration, $\mathrm{R}$, and the concentration of the spike solution, $\mathrm{P}$, according to a simple mixing formula:

$$
\mathrm{C}=\frac{\mathrm{R} \times\left(\mathrm{M}_{\mathrm{R}} / \mathrm{D}\right)+\mathrm{P} \times \mathrm{V}_{\mathrm{P}}}{\mathrm{V}_{\mathrm{C}}},
$$

where $M_{R} / D$ is the CRM sample weight (in $g$ ) corrected for moisture content, and $\mathrm{V}_{\mathrm{C}}$ and $\mathrm{V}_{\mathrm{P}}$ are the volumes of digest and spike (in $\mathrm{mL}$ ). This equation can be rearranged as follows:

$$
\frac{\mathrm{C} \times \mathrm{V}_{\mathrm{C}} \times \mathrm{D}}{\mathrm{M}_{\mathrm{R}}}=\mathrm{P} \times \frac{\mathrm{V}_{\mathrm{P}} \times \mathrm{D}}{\mathrm{M}_{\mathrm{R}}}+\mathrm{R},
$$

which has the form $y=P \cdot x+R$. If the quantities $x$ and $y$ are plotted against each other, as is shown for As and $\mathrm{V}$ in Fig. 1, P and R can be obtained from linear regression.

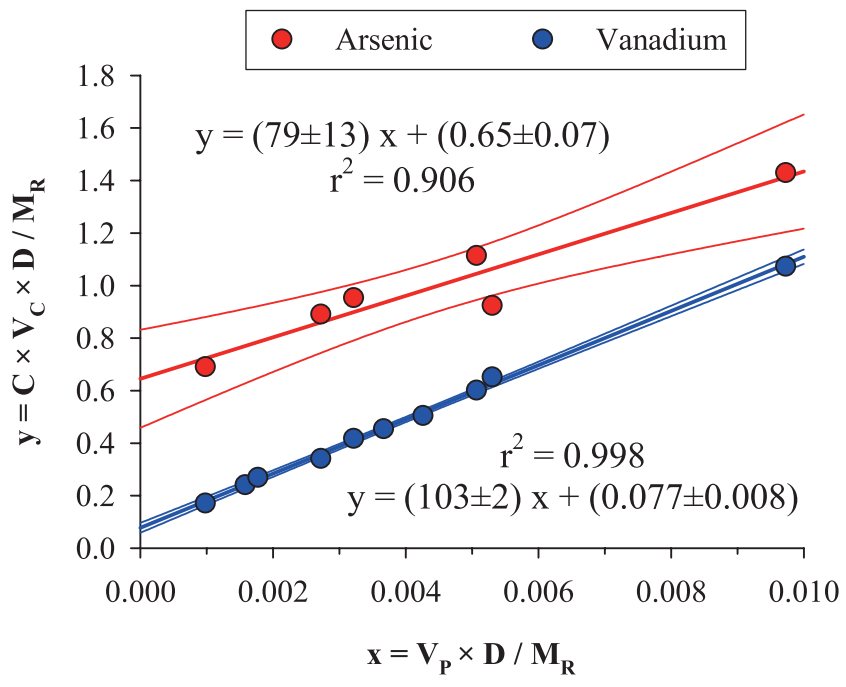

Fig. 1. Spike recovery experiments for As and V in NJV 94-5. Thin lines indicate $95 \%$ confidence intervals. Slopes of the regression lines represent recovered concentrations of the 100 $n g \mathrm{~mL}^{-1}$ spike solution. Intercepts represent recovered CRM concentrations in $\mu g g^{-1}$ (Table 3). See text for details of the linearization and the meaning of the $x$-and $y$-variables.

Independent estimates of the chemical yield can then be made by comparing $\mathrm{P}$ with the concentration of the spike solution (100 $\mathrm{ng} \mathrm{mL}^{-1}$ ) and $\mathrm{R}$ with the CRM concentration measured on unspiked samples. If the estimates agree, they can substitute for the chemical yield when certified CRM concentrations are highly uncertain (As and $\mathrm{Cr}$ ) or not available ( $\mathrm{Ni}$ and $\mathrm{V}$ ).

For $\mathrm{Cr}, \mathrm{Ni}$, and $\mathrm{V}$, chemical yields estimated from either $\mathrm{P}$ or $\mathrm{R}$ are always $\geq 90 \%$, indicating that virtually no loss occurred during digestion and, again, that the ORS worked properly. For Ni, it also confirms that our measured value is correct and that the value reported by Olssen et al. (1999) is roughly one order of magnitude too high. For $\mathrm{Cr}$, it suggests that the true CRM concentration may be lower than the certified value, whose reported uncertainty is quite large. The chemical yields of $\mathrm{Cr}$ as well as $\mathrm{Ni}$ and $\mathrm{V}$, reported in Table 3, are thus derived from regression slopes of the spike recovery experiments (Fig. 1), rather than directly measured concentrations.

For As, the estimates from $\mathrm{P}$ and $\mathrm{R}$ are also in agreement, but infer a chemical yield of only $80 \%$, in other words similar fractions of the As contributed by CRM and spike were lost during digestion $(\sim 20 \%)$ and the certified value appears to be correct. Incidentally, a procedural blank spiked with As before digestion had a chemical yield of $\sim 100 \%$. This could imply that the formation of volatile As species is facilitated by the presence of the wood sample. Concentrations of As in the core sections are not corrected for chemical yield and should be considered lower-bound values. 


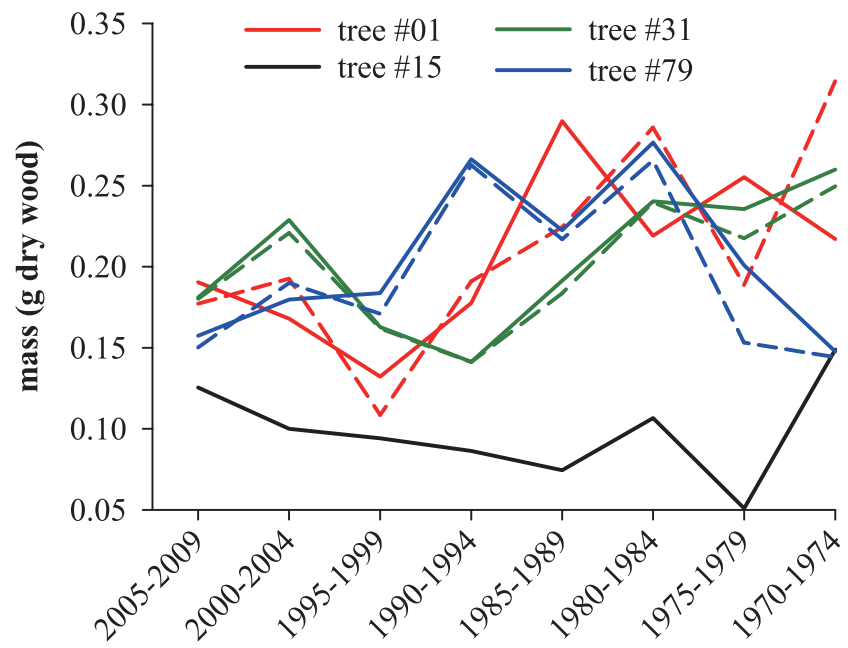

Fig. 2. Growth curves, in 5-year increments, of four eastern cottonwood trees. Dashed lines are replicate cores from the same tree. Trees \#31 and \#79 are located at two different sites outside the cancer cluster; \#01 and \#15 are located at a single site inside the cluster, just a few dozen meters apart.

The 4-metal stock solution used for the spike recovery experiments in Fig. 1 was found to contain no detectable levels of $\mathrm{Cd}, \mathrm{Co}, \mathrm{Cu}$, and $\mathrm{Pb}$, hence their measured concentrations (Table 3 ) are the average of all spiked and unspiked CRM samples. For the other metals, mean concentrations measured in the unspiked CRM samples were averaged with values of $\mathrm{R}$ determined from the intercepts of the regression lines.

\section{Application to natural samples}

Our method was specially designed for a comprehensive survey of legacy soil pollution in a region of northern Ohio that is the location of a known childhood cancer cluster (Sandusky Co. Health Dept. and Ohio Dept. of Health, 2011). The goal was to develop a protocol for the rapid and routine analysis of a wide range of metals in core sections as small as a single annual ring, at background to moderately elevated concentrations, relying on familiar and commonly available techniques.

Construction of soil pollution histories from tree increment cores, termed "dendroanalysis" (Nabais et al., 1999) or "dendrochemistry" (Sheppard and Witten, 2005), is somewhat controversial. Several controlled studies have shown that relative levels of metals in tree rings do indeed reflect concentrations in the immediate environment at the time the ring was grown (Hagemeyer et al., 1993, 1994a; Hagemeyer and Weinand, 1996). Some attempts to construct soil pollution histories based on core records appear to have been successful for ring-porous trees, such as oak, which conduct water mainly through the outermost ring (Eklund, 1995; Jonsson et al., 1997; Sheppard et al., 2007). On the other hand, diffuse-porous trees, such as spruce, conduct water-and may consequently deposit metals-across dozens of rings simultaneously (Hagemeyer and Lohrie, 1995). Moreover, strong evidence exists that metals are highly mobile in the sapwood, both along the trunk and across the rings, due to heartwood formation and lateral transport in parenchymal rays (Balk and Hagemeyer, 1994; Hagemeyer et al., 1994b; Hagemeyer and Lohrie, 1995), as well as changes in binding coefficients of the xylem cells with age (Balk and Hagemeyer, 1994; Hagemeyer and Shin, 1995). Many experts therefore assert that radial metal distributions are not well preserved in the trunk of either diffuse- or ringporous trees, even on seasonal timescales. Whereas these problems may ultimately limit the utility of dendroanalysis as a biomonitoring tool, improved analytical methods like ours can certainly help to define its capabilities.

As part of the Ohio survey, which a separate publication will relate in full detail, we collected duplicate cores of two trees (\#31 and \#79) outside and one tree (\#01) inside the cancer cluster, and a core from a second tree (\#15) at the latter site. Plotted in Fig. 2 are growth curves derived from the seven cores, expressed as the dry mass of each 5-year section. Trees \#01, \#31, and \#79 appear to have grown at comparable rates, but \#15 grew barely half as fast, despite standing close to \#01. Replicate growth curves are clearly quite similar for \#31 and for \#79, yet less so for \#01. Only one of the \#01 replicate curves broadly resembles the \#15 curve with regard to shape.

Plotted in Fig. 3A are Cd concentration profiles for the seven cores, expressed as ng $\mathrm{Cd}$ per $\mathrm{g}$ of dry wood. Once again, replicate profiles are nearly identical for \#31 and for \#79. However, while both trees grew outside the cancer cluster and at comparable rates (Fig. 2), \#31 displays steadfastly low $\mathrm{Cd}$ concentrations throughout the 40-year core, whereas \#79 has a prominent peak of $\sim 2000$ $\mathrm{ng} \mathrm{g}^{-1}$ in the 1985-1989 section. A peak of similar magnitude is visible in \#01, inside the cluster, yet in a different section (1995-1999). Notably, adjacent tree \#15 has a broad peak in the sections 1980-1989 that is more reminiscent of the one in \#79, outside the cluster. Tree \#01 does have a second peak in this section, but it is only half as large. Tentative histories of $\mathrm{Cd}$ exposure are not recorded congruently, even among trees at the same site.

A few dendroanalytical studies have observed a clear negative correlation between growth curves and metal concentration profiles within the same core (Hagemeyer and Lohrie, 1995). This may result from a simple dilution effect, but could also signify an adverse influence on growth by the metal (Zacchini et al., 2009). Conversely, positive, negative, and ambiguous correlations between growth and metal concentrations have all been observed in trees of a single species growing in the same location 

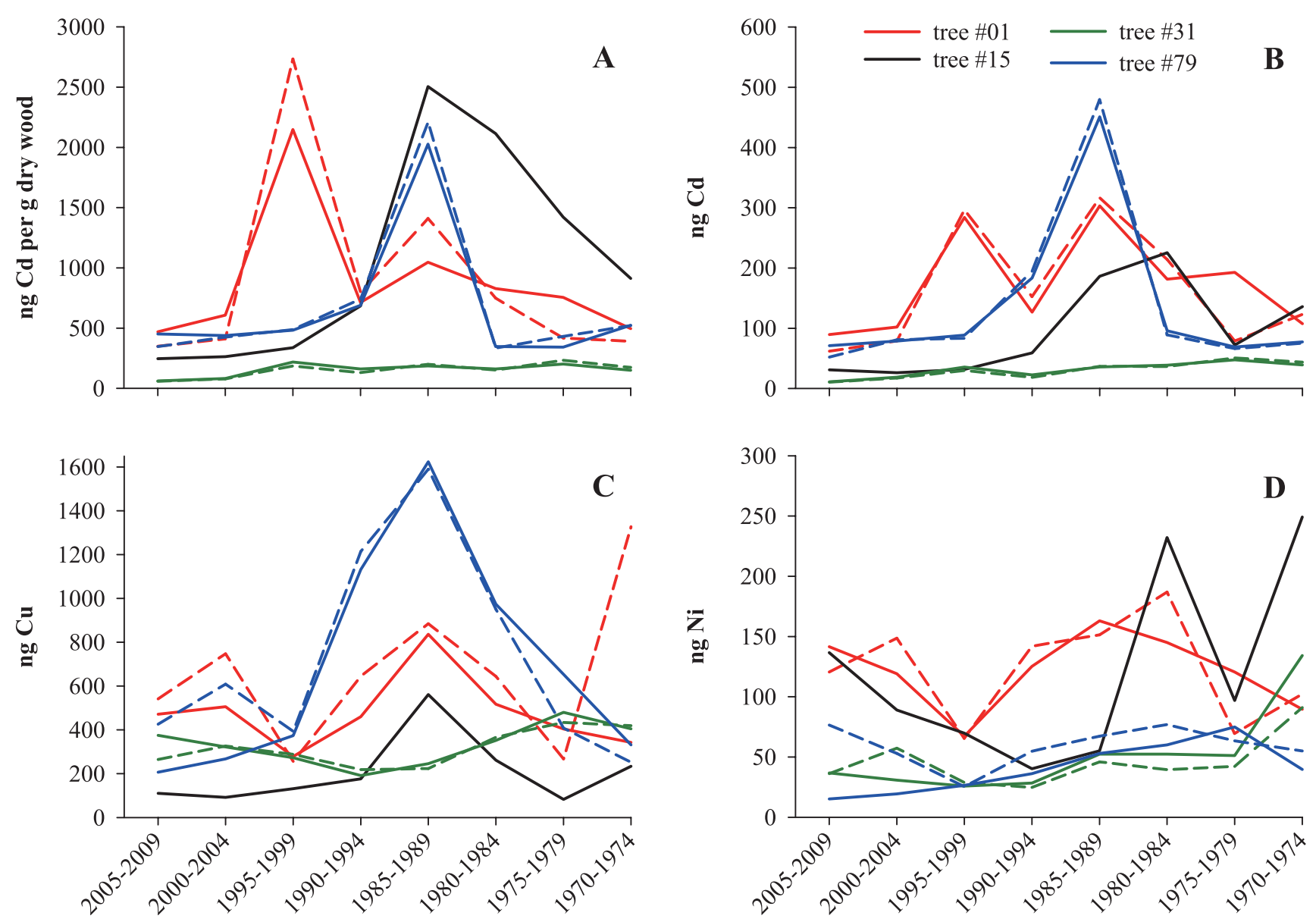

Fig. 3. Concentration ( $\left.\mathrm{ng}^{-1}\right)$ of $C d(A)$ and burden ( $\left.n g\right)$ of $C d(B), C u(C)$, and $N i(D)$ in individual 5-year core sections from four eastern cottonwood trees. Dashed lines are replicate cores from the same tree. Trees \#31 and \#79 are located at two different sites outside the cancer cluster; \#01 and \#15 are located at a single site inside the cluster, just a few dozen meters apart.

(Nabais et al., 1996). In view of possible correlations between growth and metal uptake, some researchers have proposed that core records should properly be depicted in terms of metal burden i.e., the total amount of metal (in ng) in each section (Hagemeyer and Lohrie, 1995; Nabais et al., 1996). This is calculated by multiplying metal concentrations (Fig. 3A) with the dry mass of the corresponding sections (Fig. 2), as shown in Fig. 3B. A few improvements are apparent. There is better agreement between the \#01 replicate profiles, which may indicate that dilution effects can play a role, at least within a single tree. In addition, while the late Cd peak in \#15 is still missing, the early peak is now more equal in magnitude to the one in $\# 01$. However, substantial discrepancies do persist in profiles of the $\mathrm{Cd}$ burden between trees from two sites with presumptively similar soil pollution histories (\#31 and \#79) and even between trees from the same site (\#01 and \#15). Profiles of the $\mathrm{Cu}$ and $\mathrm{Ni}$ burden (Figs. 3C and D) are in good agreement for cores from the same tree, yet different for trees from the same site; trees from the two similar sites (\#31 and \#79) are in fair agreement for $\mathrm{Ni}$, but clearly divergent for $\mathrm{Cu}$.

Figures 2 and 3 plainly illustrate that the construction of soil pollution histories from tree increment cores is problematic, whether records of metal concentration or metal burden in the wood are used. Metals appear to be highly mobile in the trunk and do not form radial distributions that are stable in time and easily interpretable. However, many studies have shown that trees growing in conditions of high metal exposure deposit more metal in the xylem (Robitaille, 1981; Berish and Ragsdale, 1985; Hagemeyer et al., 1993, 1994a; Eklund, 1995; Sheppard et al., 2007). A straightforward, albeit perhaps unsatisfactory, alternative may thus be to focus on the amount of metal accumulated over the entire life of the tree, expressed either as a burden (ng) or a concentration $\left(\mathrm{ng} \mathrm{g}^{-1}\right)$. This is demonstrated in Table 4. Four of the eight metals are omitted, namely As, Co, and V, which were largely near or below detection limit (Table 2), and $\mathrm{Cr}$, which was noisy due to mass interferences and random 
Table 4. Metal analysis of whole tree core replicates

\begin{tabular}{|c|c|c|c|c|c|c|c|}
\hline Metal & 01-C & 01-D & $15-\mathrm{B}^{\mathrm{a}}$ & 31-B & $31-\mathrm{C}$ & 79-B & 79-C \\
\hline \multirow[t]{2}{*}{$\mathrm{Cd}^{\mathrm{b}}$} & 1388 & 1324 & 768 & 250 & 245 & 1116 & 1122 \\
\hline & 841 & 786 & 976 & 152 & 154 & 682 & 722 \\
\hline \multirow[t]{2}{*}{$\mathrm{Cu}$} & 3819 & 5313 & 1651 & 2645 & 2539 & 5564 & 5844 \\
\hline & 2315 & 3157 & 2098 & 1611 & 1592 & 3403 & 3759 \\
\hline \multirow[t]{2}{*}{$\mathrm{Ni}$} & 971 & 986 & 969 & 412 & 366 & 325 & 472 \\
\hline & 589 & 586 & 1232 & 251 & 229 & 199 & 303 \\
\hline \multirow[t]{2}{*}{$\mathrm{Pb}$} & 217 & 331 & 294 & $(57)^{\mathrm{c}}$ & 76 & 74 & 86 \\
\hline & 132 & 197 & 374 & $(35)^{c}$ & 48 & 45 & 55 \\
\hline Mass $^{\mathrm{d}}$ & 1.650 & 1.683 & 0.787 & 1.642 & 1.595 & 1.635 & 1.554 \\
\hline
\end{tabular}

blanks. For each metal, the total burden is given in the first row. It is calculated by summing the amount of metal in each section over the whole core, noting that these five trees are not all exactly the same age. Detection limits were substituted for any section whose concentration does not exceed it. Total burdens were divided by the dry mass of the whole core, listed in the last row, to get total concentrations, given in every second row.

Agreement is generally good for all four metals in replicate cores from the same tree. In adjacent trees, however, total concentration agrees more closely than total burden for $\mathrm{Cd}$ and $\mathrm{Cu}$, whereas the opposite is true for $\mathrm{Ni}$ and $\mathrm{Pb}$. It probably indicates that $\mathrm{Cd}$ and $\mathrm{Cu}$ uptake are proportional to water use, yet that $\mathrm{Ni}$ and $\mathrm{Pb}$ enter the tree via a different pathway (Eklund, 1995; Saarela et al., 2005). This outcome suggests an alternative to relying on radial metal distributions in the trunk. Complete cores could be collected from many trees of one species and binned into cohorts of the same age. Depending on the metal, total concentrations or burdens may then be measured to construct a regional history of lifetime exposure. While such a strategy obviates the need for analyzing annual rings, microwave digestion demands that whole cores be divided into smaller sections and the resulting radial metal distributions, whatever their interpretation, can still be of interest. In any case, it would involve the analysis of multiple core sections for a prodigious number of trees and hence benefit more from a routine highthroughput method, like ours, than from a very sensitive but laborious one.

\section{CONCLUSIONS}

We have presented a method designed for the rapid analysis of eight trace metals in sections of 1-5 annual rings, manually dissected from tree increment cores. The wood is broken down with concentrated $\mathrm{HNO}_{3}$ in a microwave digestion unit. After overnight cooling and 100fold dilution, digests are analyzed by ICP-MS, using a He octopole reaction system for metals prone to polyatomic interferences. As a practical application, 40year increment cores of eastern cottonwood from northern Ohio were divided into eight 5-year sections and digested in a single run, along with a procedural blank and a CRM. Under routine operation, end-to-end processing of one increment core per day can be achieved, on average.

Our approach has low blanks and detection limits, equivalent to those of existing methods. Repeated analysis of the CRM gave chemical yields of $>93 \%$ for Cd, $\mathrm{Co}, \mathrm{Cu}$, and $\mathrm{Pb}$. Spike recovery experiments furthermore gave yields of $>90 \%$ for $\mathrm{Cr}, \mathrm{Ni}$, and $\mathrm{V}$, yet only $80 \%$ for As which appears to suffer some loss during digestion. The CRM concentration of $\mathrm{Ni}$ is one order of magnitude lower than a previously published value and low CRM concentrations of Co and $\mathrm{V}$ are reported here for the first time. Our method was developed for use with commonly available state-of-the-art instrumentation, but not specifically optimized for high sensitivity. However, detection limits can be lowered by adjusting the volume of acid in the digestion vessels, or the dilution factor of the digests, to allow analysis of single annual rings. The ICP-MS protocol can also be readily modified to encompass additional environmentally relevant trace metals, such as Se, $\mathrm{W}$, and $\mathrm{Hg}$, or adapted for ICP-AES to target major elements like $\mathrm{Ca}, \mathrm{Al}$, and $\mathrm{Fe}$.

Our method was validated by comparing replicate cores from single trees at three different sites and two 
cores from adjacent trees at the same site. As has been found in prior studies, the cores do not seem to preserve reliable records of metal loading in the area where they grow. On the other hand, agreement between replicate cores is much improved when total metal burdens in whole cores are considered, reflecting cumulative lifetime exposure of the tree. For some metals this quantity is affected by the mean growth rate and best expressed as a total concentration. A quick and routine analytical method such as ours may therefore facilitate the construction of soil pollution histories by sampling complete cores from many trees of one species, in the same season, and binning them into age cohorts. Furthermore, it should be beneficial for novel studies of metal mobility and fate in forest ecosystems, tree physiology, phytoremediation of soils, arboriculture etc.

Acknowledgments-Constructive comments by two anonymous reviewers led to substantial improvement of our manuscript. Oberlin undergraduate students Sonya Kaufman and Anne Nigra, and CBL REU student Kailee Potter and volunteer Katie Hoffman assisted us with the painstaking analysis of several hundred core sections. MCG thanks the Great Lakes College Association New Directions Initiative and Oberlin College for financial support. The ICP-MS laboratory of JS was operated in part with funding from the National Science Foundation. Gregory Wiles (College of Wooster) ensured the fidelity of our tree ring counting. This is UMCES contribution \#5450.

\section{REFERENCES}

Balk, G. and Hagemeyer, J. (1994) Extraction of Cd and $\mathrm{Pb}$ from stem wood of oak trees (Quercus petraea [MATT.] LIEBL.) with various solutions. Angew. Bot. 68, 191-194.

Balouet, J. C., Smith, K. T., Vroblesky, D. and Oudijk, G. (2009) Use of dendrochronology and dendrochemistry in environmental forensics: Does it meet the Daubert criteria? Environ. Forens. 10, 268-276.

Berish, C. W. and Ragsdale, H. L. (1985) Chronological sequence of element concentrations in wood of Carya spp. in the southern Appalachian Mountains. Can. J. Forest Res. 15, 477-483.

Brabander, D. J., Keon, N., Stanley, R. H. R. and Hemond, H. F. (1999) Intra-ring variability of $\mathrm{Cr}, \mathrm{As}, \mathrm{Cd}$, and $\mathrm{Pb}$ in red oak revealed by secondary ion mass spectrometry: Implications for environmental biomonitoring. Proc. Nat. Acad. Sci. USA 96, 14635-14640.

Cossa, A. (1879) Sulla diffusione del cerio, del lantano e del didimio. Gazz. Chim. Ital. 9, 118-140 (in Italian).

Edmands, J. D., Brabander, D. J. and Coleman, D. S. (2001) Uptake and mobility of uranium in black oaks: implications for biomonitoring depleted uranium-contaminated groundwater. Chemosphere 44, 789-795.

Eklund, M. (1995) Cadmium and lead deposition around a Swedish battery plant as recorded in oak tree rings. $J$. Environ. Qual. 24, 126-131.

Fritts, H. C. (1976) Tree Rings and Climate. Academic Press,
London, U.K.

Giry, C., Felis, T., Kölling, M. and Scheffers, S. (2010) Geochemistry and skeletal structure of Diploria strigosa, implications for coral-based climate reconstruction. Palaeogeogr. Palaeoclimatol. Palaeoecol. 298, 378-387.

Hagemeyer, J. and Hübner, C. (1999) Radial distributions of $\mathrm{Pb}$ in stems of 6-year-old spruce trees (Picea abies (L.) Karst.) grown for 2 years in $\mathrm{Pb}$-contaminated soil. Water Air Soil Pollut. 111, 215-224.

Hagemeyer, J. and Lohrie, K. (1995) Distribution of Cd and Zn in annual xylem rings of young spruce trees [Picea abies (L.) Karst.] grown in contaminated soil. Trees 9, 195-199.

Hagemeyer, J. and Shin, K. (1995) Extraction of $\mathrm{Cd}$ and $\mathrm{Pb}$ from stem wood of pine (Pinus sylvestris L.) trees with various solutions. Angew. Bot. 69, 55-59.

Hagemeyer, J. and Weinand, T. (1996) Radial distributions of $\mathrm{Pb}$ in stems of young Norway spruce trees grown in $\mathrm{Pb}$ contaminated soil. Tree Physiol. 16, 591-594.

Hagemeyer, J., Kahle, H., Breckle, S.-W. and Waisel, Y. (1986) Cadmium in Fagus sylvatica L. trees and seedlings: Leaching, uptake and interconnection with transpiration. Water Air Soil Pollut. 29, 347-359.

Hagemeyer, J., Lülfsmann, A., Perk, M. and Breckle, S.-W. (1992) Are there seasonal variations of trace element concentrations $(\mathrm{Cd}, \mathrm{Pb}, \mathrm{Zn})$ in wood of Fagus trees in Germany? Vegetatio 101, 55-63.

Hagemeyer, J., Lohrmann, D. and Breckle, S.-W. (1993) Development of annual xylem rings and shoot growth of young beech (Fagus sylvatica L.) grown in soil with various $\mathrm{Cd}$ and Zn levels. Water Air Soil Pollut. 69, 351-361.

Hagemeyer, J., Heppel, T. and Breckle, S.-W. (1994a) Effects of $\mathrm{Cd}$ and $\mathrm{Zn}$ on the development of annual xylem rings of young Norway spruce (Picea abies) plants. Trees 8 , 223227.

Hagemeyer, J., Schäfer, H. and Breckle, S.-W. (1994b) Seasonal variations of nickel concentrations in annual xylem rings of beech trees (Fagus sylvatica L.). Sci. Total Environ. 145, 111-118.

Hall, G. S., Yamaguchi, D. K. and Rettberg, T. M. (1990) Multielement analyses of tree rings by inductively coupled plasma mass spectrometry. J. Radioanal. Nucl. Chem. Lett. 146, 255-265.

Harju, L., Lill, J.-O., Saarela, K.-E., Heselius, S.-J., Hernberg, F. J. and Lindroos, A. (1997) Analysis of trace elements in trunk wood by thick-target PIXE using dry ashing for preconcentrations. Fresen. J. Anal. Chem. 358, 523-528.

Heckel, É. (1899) Sur la présence du cuivre dans les plantes, et les quantités qu'elles peuvent en contenir a l'état physiologique. Bull. Soc. Bot. 46, 42-43 (in French).

Hoffmann, E., Lüdke, C., Scholze, H. and Stephanowitz, H. (1994) Analytical investigations of tree rings by laser ablation ICP-MS. Fresen. J. Anal. Chem. 350, 253-259.

Jonsson, A., Eklund, M. and Håkansson, K. (1997) Heavy metals of the 20th century recorded in oak tree rings. J. Environ. Qual. 26, 1638-1643.

Martin, R. R., Zanin, J. P., Bensette, M. J., Lee, M. and Furimsky, E. (1997) Metals in the annual rings of eastern white pine (Pinus strobus) in southwestern Ontario by secondary ion mass spectroscopy (SIMS). Can. J. Forest Res. 
27, 76-79.

Martin, R. R., Naftel, S. J., Macfie, S. M., Jones, K. W., Feng, H. and Trembley, C. (2006) High variability of the metal content of tree growth rings as measured by synchrotron micro X-ray fluorescence spectrometry. X-ray Spectrom. 35 , 57-62.

Matusiewicz, H. and Barnes, R.M. (1985) Tree ring wood analysis after hydrogen peroxide pressure decomposition with inductively coupled plasma atomic emission spectrometry and electrothermal vaporization. Anal. Chem. 57, 406-411.

Nabais, C., Freitas, H., Hagemeyer, J. and Breckle, S.-W. (1996) Radial distribution of $\mathrm{Ni}$ in stemwood of Quercus ilex $\mathrm{L}$. trees grown on serpentine and sandy loam (umbric leptosol) soils of NE-Portugal. Plant and Soil 183, 181-185.

Nabais, C., Freitas, H. and Hagemeyer, J. (1999) Dendroanalysis: a tool for biomonitoring environmental pollution? Sci. Total Environ. 232, 33-37.

Narewski, U., Werner, G., Schulz, H. and Vogt, C. (2000) Application of laser ablation inductively coupled mass spectrometry (LA-ICP-MS) for the determination of major, minor, and trace elements in bark samples. Fresen. J. Anal. Chem. 366, 167-170.

Olsson, M., Viksna, A. and Helmisaari, H.-S. (1999) Multi-element analysis of fine roots of Scots pine by total reflection X-ray fluorescence spectrometry. X-ray Spectrom. 28, 335-338.

Robinson, W. O., Whetstone, R. and Scribner, B. F. (1938) The presence of rare earths in hickory leaves. Science 87, 470.

Robinson, W. O., Bastron, H. and Murata, K. J. (1958) Biogeochemistry of the rare-earth elements with particular reference to hickory trees. Geochim. Cosmochim. Acta 14, 5567.

Robitaille, G. (1981) Heavy-metal accumulation in the annual rings of balsam fir Abies balsamea (L.) Mill. Environ. Pollut. B 2, 193-202.

Saarela, K.-E., Harju, L., Rajander, J., Lill, J.-O., Heselius, S.J., Lindroos, A. and Mattsson, K. (2005) Elemental analysis of pine bark and wood in an environmental study. Sci. Total Environ. 343, 231-241.

Sandusky Co. Health Dept. and Ohio Dept. of Health (2011)
Childhood Cancer in Eastern Sandusky County, 1996-2010: A Profile of 21 Cases, Final Report, May 26.

Scribner, B. F. (1939) Spectroscopic detection of rare earth in plants. Proceedings of the Sixth Summer Conference on Spectroscopy and its Application, pp. 10-13, John Wiley \& Sons, Massachusetts Institute of Technology, Cambridge, MA, U.S.A.

Sheppard, P. R. and Witten, M. L. (2005) Laser trimming treering cores for dendrochemistry of metals. Tree-Ring Res. 61, 87-92.

Sheppard, P. R., Speakman, R. J., Ridenour, G. and Witten, M. L. (2007) Temporal variability of tungsten and cobalt in Fallon, Nevada. Environ. Health Perspect. 115, 715-719.

Sinclair, D. J., Kinsley, L. P. J. and McCulloch, M. T. (1998) High resolution analysis of trace elements in corals by laser ablation ICP-MS. Geochim. Cosmochim. Acta 62, 18891901.

Trüby, P. (1995) Distribution patterns of heavy metals in forest trees on contaminated sites in Germany. Angew. Bot. 69, 135-139.

Watmough, S. A., Hutchinson, T. C. and Evans, R. D. (1997) Application of laser ablation inductively coupled plasmamass spectrometry in dendrochemical analysis. Environ. Sci. Technol. 31, 114-118.

Wu, F., Yang, W., Zhang, J. and Zhou, L. (2010) Cadmium accumulation and growth responses of a poplar (Populus deltoids $\times$ Populus nigra) in cadmium contaminated purple soil and alluvial soil. J. Haz. Mater. 177, 268-273.

Yu, K.-F., Kamber, B. S., Lawrence, M. G., Greig, A. and Zhao, J.-X. (2007) High-precision analysis on annual variations of heavy metals, lead isotopes and rare earth elements in mangrove tree rings by inductively coupled plasma mass spectrometry. Nucl. Instrum. Meth. Phys. Res. B 255, 399408.

Zacchini, M., Pietrini, F., Scarascia Mugnozza, G., Iori, V., Pietrosanti, L. and Massacci, A. (2009) Metal tolerance, accumulation and translation in poplar and willow clones treated with cadmium in hydroponics. Water Air Soil Pollut. 197, 23-34. 